\title{
Faculty Members' Role in Establishing Direct Communication with Students to Improve Interactive Learning at Undergraduate Level: Medical Students’ Perceptions
}

\author{
Sajida Agha, Bassim Aljohani, Muhammad Anwar Khan, Reem Alsubait
}

\section{ABSTRACT}

The importance of communication by faculty member while teaching undergraduates cannot be overemphasized however its impact upon students in not well known.

This study aims to assess medical students' perception regarding teacher's contribution in direct communication if interactive learning is to be improved; and to compare responses of phase II (preclinical) and phase III (clinical) medical students.

METHODOLOGY: This cross sectional study was conducted from November 2016 to February 2017. Ethical permission was taken from the institutional research board. Investigators developed a questionnaire after a detailed literature review. Pilot study was conducted to increase the clarity of items. Responses were obtained and were analyzed statistically to get the overall medical students' perception.

RESULTS: Overall response rate was $82 \%$ (197 of 238). The role of teachers in direct verbal communication to improve learning was largely appreciated by the students. High mean score was found in the area of establishing effective channels of communication with all concerned $(x=3.81)$ that reflect the positive role of teacher in the area of effective communication. Similarly students appreciated the good listening skills $(x=3.51)$, and believe in providing fair chance of participation $(x=3.55)$. In comparison with Phase II and Phase III students, no significant difference among two groups was reported $(\mathrm{t}=-\mathbf{2 . 8 8}, \mathrm{p}=>\mathbf{0 . 0 5})$.

CONCLUSIONS: Majority of the students rated the role of faculty members as positive. Their mean perception score was above the average range. As result showed the positive responses of the students on the role of teachers in communication and learning, more emphasis on communication in interactive learning in medicine should be exercised.

KEY WORDS: Communication, Interactive learning, Medical education

This article may be cited as: Agha S, Aljohani B, Khan MA, Alsubait R. Faculty Members' Role in Establishing Direct Communication with Students to Improve Interactive Learning at Undergraduate Level: Medical Students' Perceptions. J Liaquat Uni Med Health Sci. 2017;16(03):158-63. doi: 10.22442/jlumhs.171630526

\section{INTRODUCTION}

Currently, the medical educators are debating upon poor communication skills and professionalism among the medical graduates. Consequently many institutes, to promote learning, are critically reviving methods of teaching and learning strategies and the role of the clinical educator in behavioral and skill development of medical students ${ }^{1-4}$. Although, it must be privilege and obligation of all the medical professionals to impart learning to future generations of physicians; however only few are more respectful and trustworthy, admired and perceived as professionals ${ }^{5}$ and are being modeled by the physician and trainee ${ }^{6}$.

Published literature showed that role modeling is an important aspect in the development of behaviour. $^{7}$ Poor role modeling of the teacher has been pointed out by majority of the medical students and junior physicians ${ }^{8}$.

In any higher learning institute, teaching department is also an administrative unit; effective communication between head of the department and teachers develops healthy conducive learning environment and enhances job satisfaction that may reflect positively while teaching medical students ${ }^{9}$. It has been recognized that positive outcomes can be achieved more importantly with the positive communication relationship of teacher and student ${ }^{9,10}$. Generally, medical colleges cannot ignore the prominent role that communication of faculty plays in the academic institutions of an educational environment, but also in the advancement of medical students' performance ${ }^{9}$. This is an area where most of the training institutions are lacking ${ }^{10}$. Conversely there is a knowledge gap regarding the clinical educators' role in clinical 
teaching, instructional methods and direct verbal communication with medical students in many countries including Arab countries ${ }^{11}$.

Direct communication is a linkage between faculty members and students. The direct verbal communication in the present context is defined as "a verbal communication between teacher and student on different aspect of learning and teaching for the promotion of interactive learning". The teacher ensures that the message is clearly conveyed and understood by the student. Additionally, teacher frequently and openly communicates with students to provide and receive information in a supportive and effective manner.

Several ways of verbal communication such as arranging formal or informal, individual or group sessions to provide feedback on students' performance improves interactive learning process; shared information received from higher administration can also be used by the teachers. Significant aspect of communication is providing frequent constructive feedback to students from teachers with a purpose to promote learning and behavior change ${ }^{12}$. The use of various methods and ways may improve performance, professionalism and commitment of students. Most importantly through direct communication, trust can be developed between the teachers and the students ${ }^{9}$.

Authors did not find literature that explored the role of teachers as communicator with reference to Saudi Arabia particularly in medical education. Mechanism of direct teacher-student interaction to receive and share information to improve learning is not even established in any institution to the best of authors' knowledge. This urges researchers to assess the involvement of Saudi medical teachers in direct verbal communication at undergraduate level. The responses of students may help in understanding the skills and techniques that needs to change the teaching approach and therefore may help in the organization of faculty development program on different aspects of communication. The primary purpose of this study is to assess the faculty members' role in establishing direct communication with students to improve interactive learning as perceived by medical students at College of Medicine, King Saud bin Abdul Aziz University of Health Sciences (COM, KSAU-HS), Riyadh, Saudi Arabia. We also compare perception of phase II (preclinical) and phase III (clinical) students on the role of the teacher in establishing communication with the students.

\section{METHODOLOGY}

This cross sectional survey was conducted from November 2016 to February 2017 in the College of Medicine, KSAU-HS, Riyadh, Saudi Arabia, having three campuses offering undergraduate and postgraduate programs in medicine. The Riyadh campus has two separate branches for male and female students. The integrated curriculum is taught by the basic sciences and clinical faculty through problem-based learning format in small groups setting throughout the study years. All faculty members; full time and part time appointees are expected to work as Program Based Learning (PBL) facilitator, resource provider and assessor. Full time faculty members for male section are 45 and 25 for female section. While for both male and female section 120 part time faculty members are available. Phase I, in College of Medicines, is a two year pre-professional program for all the students of medicine and health professions. Phase II consists of preclinical years, where students learn clinical skills on simulated patients and Phase III consists of clinical years where students are expected to observe and learn skills on real patients in their respective clinical departments. In this study the male and female medical students in their phase II and III, in COM, KSAU-HS, Riyadh were included. Ethical approval was taken from Institutional Review Board from King Abdul Aziz International Medical Research Centre (KAIMRC).

Sample size was calculated by using the Raosoft $\AA^{13}$. The sample size was estimated at the $95 \%$ confidence level with an estimated $50 \%$ response distribution and a margin of error of $5 \%$ adding additional $50 \%$ for nonresponse/no-availability rate. This turn out to be 238 students. Purposive sampling technique was used in which medical students who agreed to participate in the study were enrolled. A questionnaire consisted of 32 items, focusing upon the communicative behaviors of faculty members, on 5 Likert-type items from 5 to 1 for always to never was constructed. This self-administered questionnaire was pre-tested by conducting a pilot study on a group of students $(n=20)$ to increase its accuracy. After pilot study 5 ambiguous items were deleted and 3 items were rephrased. The data of pilot study was not included in the final study. To determine the internal consistency of the questionnaire, Cronbach's alpha was calculated. The Cronbach alpha for this questionnaire is 0.77 . The questionnaire was administered by the co-investigator to the students after taking written consent in their respective classes. Participants were informed that all the information will be kept confidential and data will be used anonymously only for research purpose. After data collection, responses were entered and analyzed using Statistical Package for Social Sciences (SPSS; Version 20). Continuous data e.g. age was expressed as mean and standard deviation. Categorical variables e.g. gender and responses on five point Likert scale were expressed in frequencies and 
percentages. To test the difference of responses between the Phase II and Phase III students, two-sample t-test was used. Categorization of mean scores was done and distributed into three main categories such as mean score below 2.49 was considered below average; scores between 2.50 to 3.49 were counted as average and mean scores of 3.50 - 5.00 was computed as high average. Enueme $\mathrm{CP} \&$ Egwunyenga $\mathrm{EJ}^{14}$ distribution of mean scores was taken as reference.

\section{RESULTS}

The purpose of this study was to determine the perception of medical students on the active role of teachers in direct communication and promotion of interactive learning at undergraduate level. The response rate was $82 \%$ (197 out 238 students). Out of 197 students, 126 (64\%) were from Phase III; while others $71(36 \%)$ were from Phase II. The demographic profile of the respondents is described in Table I. To assess the perception, mean and t-test were employed. Table I shows descriptive analysis of the respondents. The total sample was 197 undergraduate medical students. Among them $54 \%(n=106)$ were female and $46 \%(n=91)$ were male. The respondents' ages ranged from 20 to 32 , with an average age of 23 years. Table II-A and II-B illustrates the mean scores average mean category (2.50-3.50), showing the positive aspects of faculty members' communication in pre-clinical and clinical years. Majority (91\%) of the students rated their faculty members' communication as average ( $57 \%$ ) and above average (34\%).

Regarding first objective on different items of direct communication, students opinioned that teachers have established an effective channel with all of perception of students that is on above and

concerned (x=3.81), are good listener $(x=3.51)$, provide conducive environment for communication $(x=3.43)$, provide related information $(x=3.52)$, listen personal problems that hinders in learning $(x=3.44)$, exchange views with counterparts about the promotion of educational activities $(x=3.41)$ and encourage communication ( $x=3.43)$.

Table III demonstrates the significant difference in the perception of Phase II and Phase III about faculty members' role in direct verbal communication. Statistically no significant difference $(p=0.77>\alpha=$ 0.05 ) between the opinions of students from both levels regarding faculty role in the advancement of interactive learning is recognized. It shows that students from both pre-clinical and clinical years have similar perception about their faculty member with regard to role of direct communication in promotion of interactive learning. Although the result was insignificant but overall perception of both groups acknowledges positive role of faculty members in the direct communication at the undergraduate level.

\section{TABLE I:}

DEMOGRAPHIC PROFILE OF STUDENTS

\begin{tabular}{|l|c|c|}
\hline \multicolumn{1}{|c|}{ Variables } & $\mathbf{N}$ & Mean $\mathbf{\text { _Std. Dev }}$ \\
\hline Age & 197 & $23.6 \pm 2.82$ \\
\hline Student Batches & $\mathbf{n}$ & $\mathbf{\%}$ \\
\hline Batch 12 & 71 & 36 \\
\hline Batch 11 & 54 & 27 \\
\hline Batch 10 & 72 & 37 \\
\hline Gender & 106 & 54 \\
\hline Male & 91 & 46 \\
\hline Female
\end{tabular}

TABLE II-A: STUDENTS' VIEWS REGARDING FACULTY MEMBERS' ROLE IN THE ADVANCEMENT OF COMMUNICATION

\begin{tabular}{|l|c|c|c|c|c|c|c|c|c|c|c|}
\hline \multirow{2}{*}{\multicolumn{1}{|c|}{ Items }} & \multicolumn{2}{|c|}{ Always } & \multicolumn{2}{l|}{ Frequently } & \multicolumn{2}{l|}{ Occasionally } & \multicolumn{2}{l|}{ Seldom } & \multicolumn{2}{c|}{ Never } & \multirow{2}{*}{ Mean } \\
\cline { 2 - 12 } & $\mathrm{n}$ & $\%$ & $\mathrm{n}$ & $\%$ & $\mathrm{n}$ & $\%$ & $\mathrm{n}$ & $\%$ & $\mathrm{n}$ & $\%$ & \\
\hline Feedback session & 43 & 21.8 & 44 & 22.3 & 39 & 19.8 & 39 & 19.8 & 32 & 16.2 & 3.14 \\
\hline Information related to issue & 45 & 22.8 & 58 & 29.4 & 45 & 22.8 & 15 & 7.6 & 34 & 17.3 & 3.33 \\
\hline Effort to provide favorable environment & 46 & 23.4 & 59 & 29.9 & 43 & 21.8 & 31 & 15.7 & 18 & 9.1 & 3.43 \\
\hline Provide information regarding rules and regulations & 46 & 23.4 & 75 & 38.1 & 32 & 16.2 & 23 & 11.7 & 21 & 10.7 & 3.52 \\
\hline Discuss relevant policies & 34 & 17.3 & 67 & 34.0 & 54 & 27.4 & 28 & 14.2 & 14 & 7.1 & 3.40 \\
\hline Update students about the decisions of head & 39 & 19.8 & 36 & 18.3 & 61 & 31.0 & 22 & 11.2 & 39 & 19.8 & 3.07 \\
\hline Share related information & 52 & 26.4 & 36 & 18.3 & 70 & 35.5 & 26 & 13.2 & 13 & 6.6 & 3.45 \\
\hline Provide opportunity to discuss various issues & 34 & 17.3 & 59 & 29.9 & 59 & 29.9 & 25 & 12.7 & 20 & 10.2 & 3.31 \\
\hline Seek views of the students & 32 & 16.2 & 54 & 27.4 & 53 & 26.9 & 35 & 17.8 & 23 & 11.7 & 3.19 \\
\hline
\end{tabular}


Faculty Members' Role in Establishing Direct Communication

\begin{tabular}{|c|c|c|c|c|c|c|c|c|c|c|c|}
\hline Discussion with students & 42 & 21.3 & 53 & 26.9 & 42 & 21.3 & 31 & 15.7 & 29 & 14.7 & 3.24 \\
\hline Encourage communication among students & 54 & 27.4 & 47 & 23.9 & 44 & 22.3 & 34 & 17.3 & 18 & 9.1 & 3.43 \\
\hline Keep channels of communication open & 32 & 16.2 & 46 & 23.4 & 65 & 33.0 & 36 & 18.3 & 18 & 9.1 & 3.19 \\
\hline Use both formal and informal ways of communication & 34 & 17.3 & 52 & 26.4 & 62 & 31.5 & 30 & 15.2 & 19 & 9.6 & 3.26 \\
\hline $\begin{array}{l}\text { Establishing effective channels of communication } \\
\text { with all concerned }\end{array}$ & 76 & 38.6 & 47 & 23.9 & 46 & 23.4 & 16 & 8.1 & 12 & 6.1 & 3.81 \\
\hline Good listener & 51 & 25.9 & 47 & 23.9 & 57 & 28.9 & 36 & 18.3 & 6 & 3.0 & 3.51 \\
\hline Invite all concerned for feedback & 34 & 17.3 & 65 & 33.0 & 25 & 12.7 & 36 & 18.3 & 37 & 18.8 & 3.12 \\
\hline Open to listen personal problems & 49 & 24.9 & 43 & 21.8 & 61 & 31.0 & 34 & 17.3 & 10 & 5.1 & 3.44 \\
\hline Hesitate to initiate dialogues with his/her students & 11 & 5.6 & 56 & 28.4 & 71 & 36.0 & 41 & 20.8 & 18 & 9.1 & 3.01 \\
\hline Conceal information & 34 & 17.3 & 52 & 26.4 & 42 & 21.3 & 38 & 19.3 & 31 & 15.7 & 3.10 \\
\hline Participation of students in academic plans & 46 & 23.4 & 43 & 21.8 & 48 & 24.4 & 32 & 16.2 & 28 & 14.2 & 3.24 \\
\hline Convey suggestions to high ups & 37 & 18.8 & 42 & 21.3 & 60 & 30.5 & 28 & 14.2 & 30 & 15.2 & 3.14 \\
\hline Keep authorities informed of students' performance & 35 & 17.8 & 46 & 23.4 & 57 & 28.9 & 37 & 18.8 & 22 & 11.2 & 3.18 \\
\hline $\begin{array}{l}\text { Exchange views with counterparts about the promo- } \\
\text { tion of educational activities }\end{array}$ & 52 & 26.4 & 43 & 21.8 & 53 & 26.9 & 31 & 15.7 & 18 & 9.1 & 3.41 \\
\hline Let to seek information from every source & 23 & 11.7 & 65 & 33.0 & 46 & 23.4 & 36 & 18.3 & 27 & 13.7 & 3.11 \\
\hline Believe in open discussion & 36 & 18.3 & 64 & 32.5 & 42 & 21.3 & 32 & 16.2 & 23 & 11.7 & 3.29 \\
\hline Don't mind personal discussions & 36 & 18.3 & 45 & 22.8 & 61 & 31.0 & 41 & 20.8 & 14 & 7.1 & 3.24 \\
\hline Believe in providing fair chance of participation & 42 & 21.3 & 65 & 33.0 & 57 & 28.9 & 25 & 12.7 & 8 & 4.1 & 3.55 \\
\hline
\end{tabular}

TABLE II-B:

STUDENTS' VIEWS REGARDING FACULTY MEMBERS' ROLE IN THE PROMOTION OF COMMUNICATION

\begin{tabular}{|l|c|c|c|c|c|c|}
\hline \multirow{2}{*}{ Mean scores } & \multicolumn{2}{|c|}{ Overall Response } & \multicolumn{2}{c|}{ Phase II (Pre-Clinical) } & \multicolumn{2}{c|}{ Phase III (Clinical) } \\
\cline { 2 - 7 } & $\mathrm{n}$ & $\%$ & $\mathrm{n}$ & $\%$ & $\mathrm{n}$ & $\%$ \\
\hline Below average & 19 & 10 & 6 & 8 & 13 & 10 \\
\hline Average & 112 & 57 & 43 & 61 & 69 & 55 \\
\hline Above average & 66 & 34 & 22 & 31 & 44 & 35 \\
\hline Total & $\mathbf{1 9 7}$ & $\mathbf{1 0 0}$ & $\mathbf{7 1}$ & $\mathbf{1 0 0}$ & $\mathbf{1 2 6}$ & $\mathbf{1 0 0}$ \\
\hline
\end{tabular}

TABLE III: T-TEST SHOWS THE COMPARISON BETWEEN THE VIEWS OF BASIC AND CLINICAL SCIENCES STUDENTS ABOUT FACULTY MEMBERS' ROLE IN THE ADVANCEMENT OF COMMUNICATION

\begin{tabular}{|c|c|c|c|c|}
\hline Mean score & $\mathrm{n}$ & $\begin{array}{l}\text { Mean } \pm \\
\text { Std. Dev }\end{array}$ & t- value & $p$-value \\
\hline $\begin{array}{l}\text { Phase II } \\
\text { (Pre-Clinical) }\end{array}$ & 71 & $3.3 \pm .58$ & \multirow{2}{*}{-.28} & \multirow{2}{*}{$0.77^{*}$} \\
\hline $\begin{array}{l}\text { Phase II } \\
\text { (Clinical) }\end{array}$ & 126 & $3.3 \pm .67$ & & \\
\hline
\end{tabular}

\section{DISCUSSION}

The role of faculty member was positively perceived by the students on all items related to communication. The average and above average mean scores on most of the items reflect the pivotal role of faculty members' communication during pre-clinical and clinical years. The above average mean scores of 3.5 in items on providing information regarding rules and regulations, good listening ability and believe in providing fair chance of participation, and teachers support in terms of providing relevant information and feedback indicate a significant role of teachers in establishing ways of communication with students for the advancement of interactive learning. One study to 
assess the learner's perspective on communication in pediatric intensive care identified that only $50 \%$ of the students were satisfied with communication in education and rated it as very good. ${ }^{15}$ On the other, a study reported that medical students put more emphasis on the charismatic personality of the teacher and suggested further studies on effective teaching and strategies of effective teaching ${ }^{16}$.

Although, communication skills are a challenge for faculty members in medicine, teaching and using effective communication skills into practice is a need of the time which can be achieved through frequent teacher- learner's meeting.

In this study the average mean scores on other items reveals that faculty members emphasize on creating a favorable environment for students' learning during and after the class to increase students' motivation and their interest in learning. Moreover, students' satisfaction with faculty members on sharing of information related to learning was positively perceived. Students confirm that faculty members discuss about all the official matters concerned with students which have an impact on student's satisfaction with the work and its environment. Almost identical results has previously been reported that feedback on patient-student interaction and hospital related matters may improve student's job performance and professionalism ${ }^{10,17}$.

In addition, the finding predicted a greater role of direct communication in learning because it entails achievement, self-motivation, understanding of personal issues and proper academic planning and proper appraisal ${ }^{17,18}$. This is acknowledged by the students in this study and pointed out the teacher's interest in personal and professional matters of student to promote interactive learning and performance.

Further, when the perception of learner from Phase II and Phase III was compared, no significant difference at undergraduate medical education on the aspect of direct interaction with students was found. This insignificant result proves the crucial contribution of direct communication of teachers with students in interactive learning at all level of study as perceived by both groups. As most of the teachers conduct sessions in an integrated curriculum at the college in both Phase II and III, this insignificant result indicates that they are using similar ways of communication with students in their teaching with an intention to improve learning.

\section{CONCLUSION \& RECOMMENDATION}

It is concluded that the role of faculty members in direct communication with students in the advancement of learning is perceived effective at undergraduate level. However the sample size and the response rate were very low for this study it is therefore recommended that a multicenter larger study should be conducted including both male and female students. To prepare medical students for professional life, it is recommended that formal communication sessions between teacher and student should be included in the undergraduate activities.

\section{REFERENCES}

1. Nilsson MS, Pennbrant S, Pilhammar E, Wenestam CG. Pedagogical strategies used in clinical medical education: an observational study. BMC Med Educ. 2010; 10:9. doi: 10.1186/14726920-10-9.

2. Byszewski A, Hendelman W, McGuinty C, Moineau G. Wanted: role models - medical students' perceptions of professionalism. BMC Med Educ. 2012; 12:115. doi: 10.1186/1472-6920 $-12-115$.

3. Passi V, Johnson S, Peile E, Wright S, Hafferty F, Johnson $\mathrm{N}$. Doctor role modeling in medical education: BEME Guide No.27. Med Teach. 2013; 35(9):e1422-36.

4. Jochemsen-van der Leeuw HG, van Dijk N, van Etten-Jamaludin FS, Wieringa-de Waard M. The attributes of the clinical trainer as a role model: a systematic review. Acad Med. 2013; 88(1): 26-34.

5. Cote L, Leclere H. How clinical teachers perceive the doctor-patient relationship and themselves as role models. Acad Med. 2000; 75(11):1117-24.

6. Skeff KM, Mutha S. Role models-guiding the future of medicine. N Engl J Med. 1998; 339(27): 2015-7.

7. Kenny NP, Mann KV, MacLeod H. Role modeling in physicians' professional formation: reconsidering an essential but untapped educational strategy. Acad Med. 2003; 78 (12):1203-10.

8. Wright SM, Kern DE, Kolodner K, Howard DM, Brancati FL. Attributes of excellent attendingphysician role models. N Engl J Med. 1998; 339 (27):1986-93.

9. Shah R. Role of heads of teaching departments in the promotion of communication at postgraduate level. Institute of education \& research, Gomal University, Dera Ismail Khan. September, 2011 (published thesis). http://eprints.hec.gov.pk/ id/3175.

10. Tsang A, Harris DM. Faculty and second-year medical student perceptions of active learning in an integrated curriculum. Adv Physiol Educ. 2016; 40 (4): 446-53.

11. Jayasuriya-Illesinghe V, Nazeer I, Athauda L, Perera J. Role Models and Teachers: medical 
students perception of teaching-learning methods in clinical settings, a qualitative study from Sri Lanka. BMC Med Educ. 2016; 16:52.

12. Prozesky DR. Communication and effective teaching. Comm Eye Health. 2000; 13(35): 44-5.

13. Raosoft.com. Sample Size Calculator. [online] Available at: http://www.raosoft.com/ samplesize.html

14. Enueme CP Egwunyenga EJ. Principals' instructional leadership roles and effect on teachers' job performance: A case study of secondary schools in Asaba Metropolis, Delta State, Nigeria. J Soc Sci. 2008; 16(1):13-7.

15. Turner DA, Fleming GM, Winkler $M$, Lee KJ, Hamilton MF, Hornik CP, et al. Professionalism and communication education in pediatric critical care medicine: The learner perspective. Acad Pediatr. 2015; 15(4):380-5.

16. Rannelli L, Coderre S, Paget M, Woloschuk W, Wright B, McLaughlin K. How do medical students form impressions of the effectiveness of classroom teachers? Med Educ. 2014; 48(8):831-7.

17. Bowen L, Marshall M, Murdoch-Eaton D. Medical Student Perceptions of Feedback and Feedback Behaviors within the Context of the "Educational Alliance". Acad Med. 2017; 92(9):1303-1312.

18. Park JJH, Adamiak $P$, Jenkins D, Myhre D. The medical students' perspective of faculty and informal mentors: a questionnaire study. BMC Med Educ. 2016; 16: 4.

AUTHOR AFFILIATION:

Sajida Agha (Corresponding Author)

Associate Professor, Department of Medical Education

College of Medicine

King Saud bin Abdulaziz University for Health Sciences

Riyadh, Saudi Arabia.

Email: aghasa@yahoo.com

Bassim Aljohani

Medical Graduate

College of Medicine

King Saud bin Abdulaziz University for Health Sciences

Riyadh. Saudi Arabia.

Muhammad Anwar Khan

Lecturer, Department of Medical Education

College of Medicine

King Saud bin Abdulaziz University for Health Sciences

Riyadh, Saudi Arabia.

\section{Reem Alsubait}

Lecturer, Department of Medical Education

College of Medicine

King Saud bin Abdulaziz University for Health Sciences

Riyadh, Saudi Arabia. 